$$
\begin{array}{r}
\text { CIVILIZAÇ } \\
\text { E BARBÁRIE: SO } \\
\text { RESISTÊNO } \\
\text { DESOBEDIÊN } \\
\text { NA AMÉRICA LAT }
\end{array}
$$




\section{CIVILIZAÇÃO E BARBÁRIE: SOBRE RESISTÊNCIA E DESOBEDIÊNCIA NA AMÉRICA LATINA}


CIVILIZAÇÃO E BARBÁRIE: SOBRE RESISTÊNCIA E DESOBEDIÊNCIA NA AMÉRICA LATINA

\section{Resumo}

O objetivo principal deste trabalho é desenvolver uma reflexão a respeito do direito de resistência e da desobediência justificável em perspectiva para a América Latina. Partindo de um método hermenêutico, foram analisados os textos de bibliografia primária e de autores que se dedicaram ao problema em análise.

Palavras-chave: Civilização, barbárie, resistência, desobediência, América Latina.

CIVILIZATION AND BARBARISM: ON RESISTANCE AND DISOBEDIENCE IN LATIN AMERICA
Abstract
The main objective of this paper is to develop a reflection on the right of resistance and justifiable disobedience in perspective for Latin America. From a hermeneutical method, we analyze the texts of primary bibliography and of authors who have dedicated themselves to the problem under analysis.
Keywords: Civilization, barbarism, resistance, disobedience, Latin America. 


\section{CIVILIZACIÓN Y BARBARIE: SOBRE RESISTENCIA Y DESOBE- DIENCIA EN AMÉRICA LATINA}

\section{Resumen}

El objetivo principal de este trabajo es desarrollar una reflexión sobre el derecho a la resistencia y a la desobediencia justificable en perspectiva para América Latina. Partiendo de un método hermenéutico, fueron analizados los textos de bibliografía primaria y de autores que analizaron el problema.

Palabras clave: Civilización, barbarie, resistencia, desobediencia, América Latina.

Caio Henrique Lopes Ramiro

caioramiro@yahoo.com.br 
"Eu, que recebi um prêmio internacional da paz, penso que, infelizmente, não há outra solução que a violência para a América Latina".

Josué de Castro

\section{INTRODUÇÃO}

O objetivo principal deste trabalho é desenvolver uma reflexão a respeito do direito de resistência e da desobediência justificável em perspectiva para a América Latina. Para tanto, em um primeiro momento foi necessária uma investigação acerca do argumento do descobrimento da América e, com apoio no pensamento Enrique Dussel, foi possível uma abordagem de cunho perspectivista, que leva em consideração o olhar do Outro latino-americano, ou seja, o ponto de vista dos vencidos.

Doravante, em um segundo momento do texto, realizou-se a abordagem em sentido de uma leitura histórica do direito de resistência e, também, considerando a existência de suas imagens secularizadas surgidas na modernidade, tais como a desobediência civil e o direito a revolução. $\mathrm{O}$ objetivo de se investigar o direito de resistência se deu no sentido de um exame da possibilidade de seu reconhecimento nas práticas de luta política dos povos latino-americanos quando da tomada da terra no novo mundo.

Por fim, o último ponto do presente trabalho, partindo da possibilidade de admissão dos pressupostos de reconhecimento de um direito de resistência aos povos da América, pretende uma abordagem dos motivos de sua oposição ao modelo de Estado euro- peu, a fim de atingir uma crítica do argumento eurocêntrico da barbárie existente no continente latino-americano, com o potencial crítico de compreensão da resistência latino-americana como uma luta da sociedade contra o Estado, do ponto de vista de certo relativismo cultural e de outras formas de arranjos societários.

\section{A ILUSÃO DO DESCOBRIMENTO: A TOMADA DA TERRA E O PONTO DE VISTA DOS VENCIDOS}

De partida, faz-se necessário um argumento de ordem metodológica no sentido de que a abordagem do presente trabalho terá por pretensão se colocar na perspectiva dos vencidos. Isso talvez possa indicar, para alguns, ausência de afastamento ou objetividade científica (tão caras ao universo do positivismo), no entanto, quando se pensa a América Latina não é razoável se colocar ao lado do colonizador europeu e sua pretensão mitológica de neutralidade científica, postura que não implica negar autores e referenciais da linhagem europeia de pensamento.

Ao se marcar uma abordagem com a perspectiva de olhar dos vencidos, pode-se indicar uma aproximação do pensamento de Walter Benjamin, em suas famosas teses sobre o conceito de história, muito especialmente os dizeres de Benjamin na oitava tese ${ }^{1}$, que afirma a tradição dos oprimidos como aquela que denuncia o estado de exceção como regra, e que é preciso tomar consciência desse fato para um melhor enfrentamento das forças políticas opressoras, no caso, o exem- 
plo de Benjamin é o fascismo. Nessa primeira parte do trabalho, sem dúvida, estamos próximos do pensamento de Benjamin, no entanto, também, faremos uma leitura histórica de alguns textos de Enrique Dussel, pensador argentino, que se radicou no México em meados de 1970.

Em Eurocentrismo y modernidad, Dussel estabelece uma reflexão com alguns autores pertencentes à conhecida escola de Frankfurt. Pretende abertamente um diálogo com Jürgen Habermas, todavia, não parece arbitrário certa aproximação de sua proposta de uma abordagem do "mito da modernidade" - como uma revisita crítica ao discurso e olhar histórico-, com as reflexões de Benjamin. Para Dussel quando se trata da América Latina e sua história marcada de dor, sofrimento e resistência de seus povos "sólo una historia vista desde 'abajo' nos puede dar clara conciencia de todo esto" (Dussel 1988:488).

Ao nos aproximarmos da reflexão de Dussel temos de entrar na polêmica acerca da ideia de descobrimento da América. Por óbvio, observando-se as limitações do presente trabalho, não se tem nenhuma pretensão de esgotamento temático ou mesmo de um exaustivo inventário historiográfico a respeito da América Latina. Talvez, não desprezando a importância de uma contextualização historiográfica, seja mais importante um enfretamento de re-leitura da historiografia tradicional acerca da modernidade e suas implicações na América Latina.

Para Dussel o que se mostra funda- mental é pensar a modernidade como um mito eurocêntrico que possibilita todos os projetos coloniais europeus, com fortes impactos para os povos americanos. Nessa linha de argumentação, Dussel discorda de pensadores como Habermas, que consideram como eventos históricos decisivos para a constituição da modernidade e de seu sujeito a Reforma, a Ilustração e a Revolução Francesa (Dussel 2016a:67). Além disso, denuncia a formação de um discurso tradicional, que podemos caracterizar com Foucault e Barthes, como um discurso de poder que justifica a dominação europeia pelo descobrimento, ou seja, o europeu que chegou a América em 1492 “dice que 'des-cubrió' (quito el 'velo' a lo que estaba 'cubierto') un continente” (Dussel 1988:32). Ainda, Dussel (1988:32) destaca que:

No hay demasiada conciencia de que ambos términos indican ya una 'interpretación' que es 'en-cubridora' (que 'oculta', 'cubre') el acontecimiento histórico. Si se mira 'desde' Europa (desde 'arriba'), algo se 'des-cubre'; si se mira 'desde' el mundo del habitante de este continente (desde 'abajo'), se trata más bien de una 'invasión' del extranjero, del ajeno, del que viene de fuera; matán al váron, educan al huérfano y se 'acuestan' ('amanceban' se decía en el castellano del siglo XVI) con la mujer india.

A hipótese é de que há um verdadeiro mascaramento que forja a ilusão do descobrimento pelas noções de civilização e de progresso da cultura europeia, não apenas como um discurso histórico tomado apenas como ideolo- 
gia, mas, sim, de uma tática discursiva, um dispositivo ${ }^{2}$ de saber e de poder que se constitui como lei de formação do saber no campo político. Significa dizer que os conceitos de civilização e de progresso - forjado por certa filosofia história que passa, no século XVIII, a compreender a história como processo -, entram em cena como meios de justificar - em termos schmittianos - a tomada e possessão da terra no novo mundo. Parece-nos fundamental compreender os artifícios de poder que se formam pelas práticas discursivas, dessa maneira, em toda sociedade a produção do discurso é impactada por procedimentos e mecanismos de controle que têm "por função conjurar seus perigos, dominar seu acontecimento aleatório, esquivar sua pesada e temível materialidade (Foucault 2013:8).

Nesse horizonte de perspectiva, pode-se afirmar que o poder é plural, as práticas de poder se encontram camufladas em toda e qualquer forma discursiva, mesmo que o discurso tenha seu ponto de partida de um lugar aparentemente fora de relação com o poder (Barthes 1997:10-11). No entender de Dussel, a observação dos povos latino-americanos teria de se concentrar no discurso da modernidade, uma vez que para muitos autores esse período é um fenômeno essencialmente europeu, com raízes no pensamento kantiano acerca da necessidade da humanidade de uma saída de sua menoridade de que ela própria é culpada (Aufklärung) e, em alguma medida, também no pensamento de Hegel, tendo em vista que sua resposta à pergunta sobre o que é o iluminismo caminhou no sentido de que "la historia mundial es la autorrealización de Dios (una Teodiceia), Razón, y Libertat. Es el proceso hacia el iluminismo [...]" (Dussel 2016a:60).

O ponto de Dussel é o de que a modernidade surge com a afirmação da Europa como centro civilizado da história do mundo, contudo, não como resultado apenas dos acontecimentos intra-europeus. Nas palavras de Dussel (2016a:58):

De acuerdo a mi tesis central, 1492 es la fecha del 'nacimiento' de la modernidad, si bien su gestación envuelve un proceso de crecimiento 'intrauterino' que lo precede. La posibilidad de la modernidad se originó en las ciudades libres de la Europa medieval, que eran centros de enorme creatividad. Pero la modernidad como tal "nació" cuando Europa estaba en una posición tal como para plantearse a sí misma contra otro, cuando, en otras palabras, Europa pudo autoconstituirse como un unificado ego explorando, conquistando, colonizando una alteridad que le devolvía una imagen de sí misma. Este otro, en otras palabras, no fue 'des-cubierto', o admitido, como tal, sino disimulado, o 'en-cubierto', como lo mismo que Europa había asumido que había sido siempre. Así, sí 1492 es el momento del 'nacimiento' de la modernidad como un concepto, el origen de muy particular mito de violencia sacrificial, también marca el origen de un proceso de ocultamiento o no reoconocimiento de lo no-europeo.

Ora, da transcrição do texto do pensador argentino, percebe-se que há dois momentos discursivos a serem obser- 
vados, a saber: o primeiro o da justificativa da dominação pela ideia da superioridade cultural e, um segundo, que apresenta um argumento racional de justificação da violência. A compreensão do mito da modernidade não quer de maneira alguma negar seu caráter emancipatório - como pretendem teóricos da pós-modernidade -, mas, sim, almeja colocar em cena a figura do Outro não-europeu, que foi ocultada quando da construção do discurso de civilização culturalmente avançada e pretensamente hegemônica, que estava autorizada a "civilizar" a cultura bárbara ou selvagem encontrada pelo colonizador (Dussel 2016a). É interessante notar que a ideia de descobrimento se apresenta como uma contradição em termos quando pretende negar o Outro, uma vez que "o descubrimiento supone que algo existia ya como 'cubierto' - no se inventa de la nada: estaba ya ahí antes" (Dussel 1988:483).

Portanto, o eurocentrismo, como apresentado por Dussel, demonstra que o discurso do descobrimento carrega com ele a pretensão hegemônica da Europa de ver a sua cultura como aquela que representa a subjetividade da modernidade, o que a autoriza a se reconhecer, ilusoriamente para os outros povos, como o falar em primeira pessoa constituinte do acontecimento histórico, “'yo descubro', 'yo conquisto', 'yo envangelizo' (misioneramente), 'yo penso' (ontologicamente)" (Dussel 1988:483).

Segundo Dussel (2016a:60):

El mito del origen que está escondido en el 'concepto' emancipatorio de modernidad, y que continua subtendiendo la reflexión filosófica y muchas otras posiciones teóricas en el pensamiento de Europa y Norteamérica, tiene que ver sobre todo con la conexión del eurocentrismo con la concomitante "falacia del desarrollismo". La falacia de desarrollismo consiste en pensar que el patrón del moderno desarrollo europeu debe ser seguido unilateralmente por toda otra cultura.

O que se pretende é uma abordagem crítica do discurso eurocêntrico e desenvolvimentista que acobertam práticas de toda sorte de violências no continente americano. Nesse momento, é interessante levar em consideração a construção do Outro não europeu como o selvagem ou o bárbaro. Partir das figuras do selvagem e do bárbaro pode nos ajudar a melhor compreender a formação do discurso hegemônico e de dominação, constituído pela Europa a fim de relevar seu modo de vida como sendo aquele em que se materializa a civilização. Nesse assunto, mostra-se significativa a abordagem que Foucault faz desses dois personagens ao considerar o contexto histórico do século XVIII, especialmente no que diz respeito ao momento constituinte como aquele em que os agentes políticos terão de dar conta das relações tanto da ordem da lei quanto da ordem da força (Foucault 2010:162).

De acordo com tal perspectiva, ao nos aproximarmos de uma investigação a respeito das figuras históricas do selvagem e do bárbaro, estamos de fato também nos preocupando, de alguma maneira, com categorias jurídicas que dizem respeito à ideia de constituição e, também, do Estado. Foucault parte 
da concepção de uma filosofia da história como filosofia do tempo cíclico surgida como já mencionado no século XVIII -, que colocam em relação às ideias de constituição e de força. Conforme Foucault (2010:162):

Essa ideia de constituição, na literatura histórica que se vê formar-se em torno da reação nobiliária, é de certo modo, médica e militar ao mesmo tempo: relação de força entre o bem e o mal, relação de força também entre os adversários. Esse momento constituinte que se trata de reencontrar, deve-se alcançá-lo pelo conhecimento e pelo restabelecimento de uma relação de força fundamental. Trata-se de instaurar uma constituição que seja acessível não pelo restabelecimento de velhas leis, mas por algo que seria uma revolução das forças - revolução no sentido em que, precisamente, se trata de passar do auge da noite para o auge do dia, do ponto mais baixo para o ponto mais alto.

Ao que parece Foucault pretende uma revisita crítica aos fundamentos de constituição do estado moderno. Michel Foucault estabelece um diálogo com Boulainviliers e aponta que para esse pensador há um primeiro momento de juridicidade, do qual tenta se afastar (antijuridicismo) e um momento em que o desafio será um enfretamento com a natureza (antinaturalismo), ou seja, seu desafio será o homem natural. Para Foucault (2010:163):

O grande adversário desse gênero de análise (e é nisso também que as análises de Boulainvilliers vão se tornar instrumentais e táticas) é o homem natural, é o selvagem, entendido em dois sentidos: o sel- vagem, bom ou mau, esse homem natural que os juristas ou os teóricos do direito criaram, antes da sociedade, para constituir a sociedade, como elemento a partir do qual o corpo social podia constituir-se.

De acordo com Foucault o selvagem é uma criação discursiva que também tem por objetivo afastar outra imagem de selvagem, criada agora pela racionalidade econômica e que vê nessa figura o homem natural que pratica trocas dos produtos de seu trabalho por outro produto, assim:

o que o discurso histórico-político de Boulainvilliers e de seus sucessores quis, pois, conjurar foi, a um só tempo, o selvagem teórico-jurídico, o selvagem saído das florestas para contratar e fundar a sociedade, e foi igualmente o selvagem bomo oeconomicus que é destinado à troca e ao escambo (Foucault 2010:163).

Há um par construído nesse período que se refere ao homem natural, o selvagem teórico-jurídico do pacto originário, bem como o homem das trocas mercantis do ponto de vista econômico, o que podemos caracterizar essencialmente como o homem das trocas, o trocador de direitos ou de bens. Do ponto de vista da troca dos direitos, o que se funda é a sociedade e a soberania. No que diz respeito aos bens materiais e de consumo, o que se constitui é o corpo social, marcadamente econômico (Foucault 2010:164). Dessa forma, estamos diante da construção do discurso histórico e político que compreende a história como progresso e a saída do selvagem de sua condição natural de selvageria, colocando-se em uma relação de convívio de tipo social, 
e que é compreendida como avanço cultural.

No entanto, existe outro personagem elementar da tática discursiva que se opõe ao selvagem, esse oponente é o bárbaro. Essa figura só pode ser compreendida quando se leva em consideração a existência de uma civilização, porquanto ele se encontra fora da noção de civilidade (Foucault 2010:164).

Dirá, então, Foucault (2010:164):

Não há bárbaro, se não há em algum lugar um ponto de civilização em comparação ao qual o bárbaro é exterior e contra o qual ele vem lutar. Um ponto de civilização - que o bárbaro despreza, que o bárbaro inveja - em comparação ao qual o bárbaro se encontra numa relação de hostilidade e de guerra permanente. Não há bárbaro sem uma civilização que ele procura destruir e da qual procura apropriar-se. O bárbaro é sempre o homem que invade as fronteiras dos Estados, é aquele que vem topar nas muralhas das cidades. O bárbaro, diferentemente do selvagem, não repousa contra um pano de fundo de natureza ao qual pertence. Ele só surge contra um pano de fundo de civilização, contra o qual vem se chocar. Ele não entra na história fundando uma sociedade, mas penetrando, incendiando e destruindo uma civilização.

A longa transcrição se justifica pela exemplar definição de bárbaro dada por Foucault e, muito especialmente, pelas pretensões do presente texto, ao retirarmos o cenário europeu da análise foucaultiana, talvez coubesse a pergunta, considerando a conjuntura dos processos de dominação colonial, quem é bárbaro?

Existe uma tradição antropológica de discussão acerca da figura do bárbaro e da barbárie que descreve algumas imagens possíveis para a compreensão desse personagem. Podemos ficar com a proposta de Foucault e pensar o bárbaro como aquele que necessariamente precisa de um contexto de civilização para existir. Francis Wolff (2004, p. 23), expõe três sentidos para os conceitos de bárbaro e barbárie, e essas figuras seriam pensadas a partir de um sentido de civilização e civilidade, desenvolvimento espiritual ou cultural e, por fim, "a humanidade do sentido moral".

Destaca Wolff (2004:24) que:

O primeiro tipo de bárbaro parece pertencer a um estágio arcaico de socialização; o segundo, a um estágio arcaico da cultura; e, mais grave ainda, é a um estágio pré-humano que o terceiro parece pertencer: é o homem que permaneceu em estado selvagem, que se tornou, ou tornou a ser, desumano.

Assim, mostra-se interessante considerar que a figura do bárbaro depende de uma noção de civilização para se constituir ou, se preferirmos, o bárbaro pode ser compreendido como um constructo da civilização, tendo em vista que será forjado por um discurso de poder enquanto filosofia da história que coloca a Europa no centro do processo civilizador do mundo ocidental. Nesse sentido, a figura do Estado de modelo europeu, entendido como o monopólio jurídico da violência que regulamenta toda a ação política com a possibilidade de uso legítimo da força, 
coloca-se no centro do palco político e se reivindica como instância capaz de garantir segurança e desenvolvimento da cultura e das relações sociais, significa dizer como sujeito que pode assegurar o progresso da civilização.

Ao que parece, a história de todos os processos coloniais pode ser considerada como a construção de um discurso daqueles que representam $a$ civilização e que estaria legitimado e legalmente autorizado a "civilizar" os bárbaros, uma tática discursiva a fim de justificar a dominação e a tomada da terra e da riqueza dos povos. De acordo com Francis Wolff, um exemplo significativo de barbárie praticada em nome da civilização é exatamente a dos colonizadores, a saber:

Alguns povos que Colombo encontrou eram considerados bárbaros porque viviam nus e desconheciam a escrita. Outros, como os astecas ou maias, visivelmente pertenciam a grandes civilizações complexas e urbanizadas, mas eram tidos como bárbaros porque praticavam uma religião cujos ritos incluíam sacrifícios humanos em massa. Mas em proporções maiores, e em nome da civilização cristã, todos esses povos foram reduzidos à escravidão, torturados, massacrados, e sua cultura, seus templos e suas estátuas foram destruídos pelos espanhóis, que, encantados, com o ouro, cometeram ali o primeiro grande genocídio da história moderna (Wolff 2004:27).

O discurso do "civilizador" (colonizador) se oferece como uma homília de superioridade, no sentido de que ele é quem irá levar a civilização (ou a verda- deira religião) aos povos por ele considerados bárbaros ${ }^{3}$. A partir do ponto de vista do civilizado, dada sua superioridade cultural, há uma autorização para tratar os outros povos e suas culturas como inferiores e, ainda, articular um argumento que irá retirar qualquer possibilidade de culpa pelas práticas de destruição e submissão dos povos, uma vez que "eles nos devem gratidão, já que contribuímos para arrancá-los de sua barbárie - ou da ignorância, ou do paganismo" (Wolff 2004:28).

Ora, resta claro que $a$ civilização é um constructo discursivo que serve para beneficiar as práticas de sujeição dos povos, com a valorização de si pelo civilizado. Dussel (1988:484) ressalta que:

Tanto 'inventar' como 'des-cubrir', 'conquistar' o 'evangelizar' tienen al europeo como 'centro' (el 'yo' constituynte). Pero si efectuamos uma revolución copernicana y dejamos de situarmos desde la tierra (el 'yo' europeo) y miramos e interpretamos todos desde el mundo del primitivo habitante americano (el sol: el 'yo' amerindio), todo cobra nuevo sentido (desde bajo).

Diante do que restou dito até aqui, parece claro que o discurso do civilizador entre na esfera de justificação racional de uma decisão soberana acerca do reconhecimento ou a negação de direitos civis e políticos aos povos não-europeus. Esses direitos, que decorrem do reconhecimento/pertencimento ao Estado-nação civilizado, são exatamente aqueles que serão atingidos pela decisão soberana, e negados aos povos considerados bárbaros. Desse modo, essa decisão abre um espaço de 
exceção, que reconhece e cria um espaço vazio de normatividade, onde a norma se aplica por desaplicação, espaço anômico em que "tudo é possível", um ambiente biopolítico em que a vida dos povos ameríndios se encontra exposta a toda espécie de violência ${ }^{4}$ e a morte.

Aqui se mostra oportuno nos aproximarmos da reflexão de Carl Schmitt a respeito do estado de exceção e da tomada da terra. Schmitt parte de uma análise da estrutura de ordenação do espaço político na sociedade capitalista, destacando o espaço de vigência do Nomos soberano, dando ênfase ao caráter territorial, ou seja, a tomada da terra (Landnahme), mas, também, a ordenação jurídica (Ordnung) do território (Ortung), trinômio que se opera pela nacionalidade (nascimento/nação).

Toda ordenação no Jus publicum europeu há de conservar a tomada da terra como sua característica fundamental, seu nomos por excelência, a garantia da estrutura espacial e a unidade da ordenação e do assentamento (Schmitt 2005:186). Verifica-se do diagnóstico schmittiano que o direito público europeu se constrói em uma perspectiva que pretende legitimar a estrutura do Estado-nação a partir de uma organização jurídica da política nos termos de território (Territorium), ordenamento (Ordnum) e nascimento (Geburt), o que nos coloca diante dos elementos fundamentais para o reconhecimento do Estado-nação da modernidade. Esse último, para Schmitt é o substituto do Papa - que ordenava as cruzadas como a decisão para a tomada e possessão da terra de povos não cristãos - e, além disso, o jus publicum europeu, apresenta- -se como um discurso jurídico que se pretende legitimador da tomada da terra, especialmente no "novo mundo" por meio do "descobrimento" e ocupação, garantindo as posses coloniais das potências europeias por títulos jurídicos legais (Schmitt 2005:116-119).

Conforme Schmitt (2005:122):

O título jurídico da occupatio responde a realidade de então uma vez que pressupõe que o solo europeu de soberanos e povos europeus é distinto, segundo o Direito das Gentes, de outro solo de "Ultramar”. O solo do novo mundo pode ser ocupado livremente. Em relação com essa tese, os juristas dos séculos XVII e XVIII supõe praticamente que o solo do Novo Mundo só é ocupável livremente por Estados europeus e, desde logo, só de forma que o solo colonial não chegue a ser idêntico, em virtude da ocupação colonial ao território estatal europeu do ocupante, senão que permaneça distinto do mesmo, tanto que se trate de colônias de comércio ou de territórios de colonização ${ }^{5}$.

Além disso, de acordo com Schmitt o conceito de descobrimento também serve de justificação - inclusive jurídica -, para tomada e possessão da terra em territórios ultramar, portanto, tomada de terras não-europeias (Schmitt 2005:123). O descobrimento opera como um título jurídico e fundamenta a descoberta dos soberanos cristãos de terras, ilhas e mares até então desconhecidos e agora passíveis de serem adquiridos perante a ordem internacional e o direito das gentes, centrado na Europa (Schmitt 2005:123) ${ }^{6}$. 
Schmitt (2005:123-124) enfatiza que:

O fato é que o sentido do título jurídico "descobrimento" reside na alegação de uma posição historicamente mais elevada do descobridor frente ao descoberto, uma posição que era distinta frente aos habitantes da América do que frente aos antigos povos não-cristãos, como árabes, turcos e judeus, contanto se eram considerados hostes perpetui ou não. Desde o ponto de vista do descoberto, o descobrimento como tal nunca é legal. [...] Os descobrimentos são levado a cabo sem a autorização prévia do descoberto. Por isso, o título jurídico do descobrimento se apóia em uma legitimidade mais elevada. Só pode descobrir quem, no nível espiritual e histórico, é suficientemente superior para compreender o descoberto com seu saber e sua consciência.

Para Schmitt a expressão nomos não carrega apenas o sentido de lei como algo que funda e significa o direito, mas apresenta acepções como o de tomar, conquistar; distribuir e dividir o conquistado e, por fim, explorar o que foi tomado, por conseguinte, opera como uma violência prévia, assim, a expressão nomos da terra terá o sentido concreto de uma nova tomada da terra e, por consequência, "uma nova divisão, distribuição e repartição da terra" (Schmitt 2014:21). De tal modo, com o termo nomos Schmitt pretende destacar o problema espacial de ordenação do mundo.

Ora, reproduzir o discurso de que os povos ameríndios foram descobertos é justificar as pretensões do colonizador e de sua superioridade civilizatória.
Desse modo, há que se representar a história dos povos da América Latina como uma perspectiva de resistência ao universo cultural europeu, considerando o colonizador não como um "descobridor", mas, sim, como um invasor, um intruso que justificou política e juridicamente toda a sorte de violências praticadas aos povos não-europeus, um "desejo metódico de massacrar uma etnia e todos os indivíduos (homens, mulheres, crianças) que dela faziam parte, pelo simples fato de dela fazerem parte" (Wolff 2004:29).

Do mesmo modo, Dussel (1988:484) caracteriza o europeu como um intruso, a saber:

Del latín intruo (meterse violentamente en el interior), intrusión significa penetrar en un mundo, el mundo del otro, sin derecho, sin permiso, 'entrometerse'. Para aquel gran rebelde $-\mathrm{y}$ teólogo popular de la liberación -, los europeos eran en nuestro continente 'intrusos'. Pero el intruso había invadido, ocupado, dominado un espacio: el espacio del mundo, de la cultura, de la religión, de la historia del hombre americano.

Dessa maneira, a Europa não ocupa ou descobre as terras estrangeiras de ultramar, mas, sim, as invade, as toma para si. Só a partir de tal perspectiva se torna possível compreender a história de luta, de sofrimento e de resistência dos povos latino-americanos sem a ilusão de que sua cultura representa, por excelência, a barbárie. Pode-se nesse caminho, pretender uma investigação acerca dos fundamentos do direito de resistência e da desobediência que também foram praticadas em nosso con- 
tinente, o que será objeto de análise a seguir.

\section{NOTAS SOBRE DIREITO DE RESIS- TÊNCIA E DESOBEDIÊNCIA JUSTIFI- CÁVEL}

Em primeiro lugar, importa considerar que o objetivo a ser alcançado nessa parte do trabalho permanece vinculado ao tema escolhido, mas que envolve agora uma abordagem do direito de resistência e da desobediência civil, em perspectiva para a América Latina. Entretanto, dada a riqueza do tema, e, também, sua dificuldade, não se tem a pretensão de esgotamento, e sim, de um breve inventário dos argumentos teóricos em torno da temática, com a observação, no que for possível, de seu desenvolvimento histórico. Igualmente, não ingressaremos na polêmica teórica a respeito da possibilidade de caracterização do direito de resistência e da desobediência civil como direitos fundamentais, haja vista que esse seria problema para um trabalho próprio.

Poderíamos de partida concordar com Franz Neumann (1969) que em um primeiro momento a questão em análise parece de fácil abordagem, todavia, na medida em que nos debruçamos e aprofundamos as reflexões a seu respeito, as dificuldades só fazem aumentar. Além disso, por mais que tenhamos oportunidade de considerar que o problema da resistência e da desobediência sempre esteve aí, significa dizer que do ponto de vista da história do pensamento político há possibilidade de considerá-lo como um tema bastante antigo (Neumann 1969:165). Sem nenhuma arbitrariedade, poderíamos apontar já no seminal texto trágico de Sófocles - Antígona -, a utilização do expediente da resistência pela heroína que dá título à tragédia, quando Antígona se opõe ao edito temporal de Creonte - seu tio-, que ordena que não se guarde os ritos fúnebres a seu irmão Polinice, uma vez que esse último fora considerado um traidor da cidade de Tebas, no entanto, o ponto da resistência e da desobediência, no que diz respeito à filosofia e teoria do direito "sempre representou uma espécie de assunto proibido no amplo repositório de teorias, estruturas explicativo-compreensivas e noções que costumamos chamar de doutrina jurídica" (Matos \& Souza 2014:150).

Nessa linha de argumentação, a temática em análise se assemelha com a ideia do estado de exceção quando está em questão a abordagem jurídica de seu estatuto teórico. O direito de resistência, para alguns autores, estaria na base teórica de sustentação de suas imagens secularizadas que derivariam dele, a saber: o direito a revolução e a desobediência civil. Geralmente, os fundamentos teóricos de justificação de um direito de resistência são apresentados levando em consideração a ideia de direito natural, direitos inalienáveis e de uma teoria da justiça, exercíveis dentro de uma circunstância concreta contra um poder político opressor que se materializa na forma estatal, chegando ao extremo de justificação do tiranicídio (Neumann 1969:165).

De acordo com Patricio Carvajal (1992:65-66):

$\mathrm{O}$ direito de resistência tem uma base doutrinária sólida e precisa, 
fundada no direito natural e em uma teoria da justiça, com o qual os diversos graus de resistência, desde a resistência passiva ao tiranicidio, tem fundamentos éticos concretos, o que torna possível invocar seu exercício sempre legitimo de tal direito. Deste modo, em relação ao direito a revolução e a desobediência civil, poderíamos argumentar que se trata de manifestações ou condutas políticas que derivaram do direito de resistência devido, entre outras causas históricas, ao processo inexorável de secularização da sociedade moderna.

Não se quer afirmar com a transcrição supra que tal direito existe apenas na modernidade. Já na antiguidade grega, a partir do texto de Sófocles, muito se discutiu a respeito da possibilidade da resistência e da desobediência, com o extremo da derrubada de uma tirania e do regicídio. $\mathrm{Na}$ compreensão de Franz Neumann (1969:195-166), mesmo que se possa considerar o fato como um erro histórico, a primeira manifestação da possibilidade da resistência se apresenta com o assassinato de Hiparco, filho de Pisístrato, regicídio cometido por Harmódio e Aristogíton (514 a.C.), em defesa da liberdade.

No texto de Neumann (1969:166) observa-se:

Sabemos, contudo, que o crime foi inteiramente motivado pelos ressentimentos pessoais contra o tirano e não por considerações políticas diretas. Mesmo assim foi desse assassinato que nasceu a poderosa tradição que continuou até o século XVII (quando nasceu o absolutis- mo secular) e que recebeu um novo impulso com o advento do totalitarismo.

Nota-se uma origem antiga da ideia de resistência, mas o entendimento dessa última como um direito parece sofrer uma inflexão na aurora da modernidade. Logo, a sustentação teórica de um direito à resistência e a desobediência civil são buscados em autores da modernidade, muito especialmente em pensadores do liberalismo político, como é o caso de John Locke, que fala abertamente a respeito da resistência em sua obra ${ }^{8}$.

Nos moldes em que se apresenta a questão, com o aparecimento dos Estados modernos, após a ruptura e desencantamento do mundo teológico-eclesiástico, o debate se consolida em torno ao modo de se justificar a figura da soberania e do Estado, também no que diz respeito a suas estruturas e sua relação com os indivíduos que constituem o corpo político. Com isso, alguns temas que anteriormente ficaram obscurecidos no cenário de discussão passam a fazer parte da pauta, dentre eles estão os tópicos da resistência e da desobediência, que serão abordados por um prisma múltiplo de expectativas, que vão desde a questão acerca do dever de obediência ao Estado, considerando mandamentos jurídicos que estão em desacordo com a consciência do indivíduo no que diz respeito ao seu senso moral, conforme defendia Thoreau (2012) ${ }^{9}$; ou, também, do ponto de vista apresentado por Carvajal, que leva em consideração um aspecto de consciência moral, agora atrelado ao conceito de justiça. 
Um ponto importante a se considerar está vinculado a ideia de subordinação à ordem estatal, que na modernidade passa a ser desempenhada por um sistema normativo que garantiria a ordem e a segurança dos indivíduos, devido ao fato de que o Estado é monopolizador da violência, que passará, em termos weberianos, a ser exercida como uso legítimo da força, quando de sua configuração em um Estado de Direito. O pacto de submissão irá configurar os papeis dos atores no contexto do cenário político da modernidade e determinará as figuras do indivíduo, da sociedade e do próprio Estado.

$\mathrm{Na}$ modernidade se desenvolve a ideia de limites a atividade estatal no que diz respeito a salvaguardas das liberdades individuais. Com o aparecimento das declarações de direitos - em especial com o Bill of Rights da declaração da Virgínia de 1776 e a Declaração de Direitos do Homem e do Cidadão francesa de 1789 -, é no século XVIII - com as primeiras imagens dos direitos humanos, cuja fundamentação se dá na ideia de direito natural -, que para alguns autores se dá a pretensão de limitação do Estado com contornos jurídico-positivos e históricos. Consequentemente, os documentos jurídicos das declarações da Virgínia de 1776 e a da constituinte francesa de 1789 atestam a hipótese de que a ideia iluminista de matriz kantiana de respeito aos indivíduos como fins em si e reconhecimento de direitos universais do homem e do cidadão e, doravante, dos direitos humanos, toma a forma histórica com sua positivação nos ordenamentos dos Estados nacionais, impactando a con- duta humana, que a partir de agora será orientada pela ordem normativa, uma vez que o cidadão dos Estados de Direito nacionais é o destinatário por excelência dos agora chamados direitos fundamentais (Bulygin 1987:79).

A partir desse momento é que o constitucionalismo moderno começa, então, a reconhecer as dimensões de direitos. Os primeiros estão ligados aos direitos de liberdade com tendência a limitar, como já mencionado, o poder soberano, caracterizando-se como direitos civis, marcados por uma propriedade negativa de defesa do indivíduo em relação ao poder soberano; e políticos, e aqui a ideia dos direitos passa também a considerar uma perspectiva positiva que será representada pela possibilidade de participação e reivindicação política (autonomia). Esse último aspecto no interessa mais de perto, tendo em vista sua ligação com o tema da resistência e da desobediência, como formas de contestação do pacto originário por descumprimento da promessa associativa de asseguramento de direitos ou meios para a realização dos mesmos.

Não obstante, há que se considerar a perspectiva eurocêntrica de tal abordagem, que tem por local de atuação o cenário europeu de passagem dos Estados absolutistas ("Eu-Monarca") para o império do direito, com a constituição, a partir dos direitos do cidadão, da categoria sujeito de direito que se pretende universal. Importa notar no que se refere ao direito de resistência e a desobediência justificável, do ponto de vista histórico, um forte elemento 
decisório para a análise conjuntural que autorizaria a utilização de um direito de resistir.

Franz Neumann destaca que em todas as teorias, desde a antiguidade:

Só há um problema que não pode ser respondido: quem decide se e quando existe um direito para resistir.

No caso dos antigos: quem decide o que exige o bem da polis; para as teorias medievais, cabe à Igreja ou ao poder secular a autoridade para chegar a uma decisão; nas lutas monarcômacas, quem decide é o partido religioso; nas chamadas teorias democráticas, isso cabe ao povo (Neumann 1969:169).

Em que pese à interessante questão do decisionismo do direito de resistência - o que poderia nos remeter novamente ao pensamento de Schmitt a respeito se é a decisão o elemento jurídico por excelência no que tange a soberania, discussão para a qual não há espaço no presente trabalho -; ao que parece é uma circunstância de opressão que irá autorizar a decisão a respeito de resistir e desobedecer à ordem normativa estatal. Nessa linha, o direito de resistência seria aquele em que um indivíduo, um grupo ou um povo teriam acesso, por decisão, na medida em que estiverem diante de práticas de opressão e violência, de um poder ilegítimo ou que viole os direitos/garantias fundamentais.

Dessa forma, na compreensão de Carvajal (1992:68):

[...] O termo em si 'direito de resistência' (ius resistendi; Widerstandsrecht) tem um preciso significado na história do pensamento jurídico: a limitação do poder da autoridade pública e do Estado e a custódia da liberdade da comunidade. No fundo se trata da conservação do bem comum da sociedade (justiça) e do justo e reto ordenamento político-jurídico do Estado em qualquer de suas formas (liberdade).

Ora, se na modernidade se reconhece a figura do sujeito de direitos universal, fundamentalmente após o advento da declaração de direitos do homem e do cidadão de 1789, caberia a pergunta se as práticas de oposição dos povos ameríndios às violências perpetradas pelos "civilizadores" na América Latina poderiam ser compreendidas como barbárie ou seria a mais pura resistência ao invasor? Uma objeção possível seria a de que o homem de direitos aparece em tempo histórico posterior, todavia, como se tentou apresentar nesse tópico, há práticas de resistência ao longo do que se compreende por progresso histórico, o que invalidaria a oposição.

A opção aqui é de uma compreensão histórica do conceito de resistência e de contestação do discurso que configura as bases de reconhecimento do início da modernidade, conforme pretende Dussel. Na perspectiva da história dos conceitos, esses últimos "fundamentam-se em sistemas político-sociais que são, de longe, mais complexos do que faz supor sua compreensão como comunidades lingüísticas organizadas sob determinados conceitos-chave" (Koselleck 2015:98).

Nessa linha de argumentação, há possibilidade de abordagem dos conceitos de resistência e desobediência como aproximados da ideia de direito em um 
contexto que se coloca fora da quadra histórica da historiografia tradicional da modernidade, não só por existir uma narrativa da história antiga a respeito da resistência, da desobediência justificável (Antígona), do regicídio e do tiranicídio, mas, sobretudo, pela possibilidade de nos valermos de uma história dos conceitos enquanto método de abordagem das fontes "que atenta para o emprego de termos relevantes do ponto de vista social e político e que analisa com particular empenho expressões fundamentais de conteúdo social e político" (Koselleck, 2015:103). Destarte, por mais que a expressão direito obtenha, para alguns, o sentido de limitação ao arbítrio, inclusive do soberano e, por consequencia, haveria uma imagem de resistência a injustiça somente na modernidade, do ponto de vista de uma história dos conceitos aproximada à perspectiva de uma história social ${ }^{10}$, não parece arbitrário a investigação acerca da possibilidade de atuação dos conceitos de resistência e desobediência no período de tomada da terra na América Latina.

As pretensões da última parte do presente trabalho caminharão no sentido de investigar a relação entre a construção do discurso antropológico-político acerca do selvagem e do bárbaro como táticas de dominação e às práticas de resistência dos povos latino-americanos.

\section{“SEM FÉ, SEM LEI, SEM REI" E CON- TRA O ESTADO}

Se admitirmos os pressupostos apresentados até aqui, a saber: que a ideia de descobrimento é uma tática discur- siva que encobre um processo de invasão colonizadora e de imposição de uma cultura eurocêntrica e, ademais, de que a resistência surgida no continente americano pode ser compreendida dentro de uma perspectiva de direito, a partir de uma leitura histórica do conceito, podemos então nos aproximar de uma interessante reflexão a respeito do poder e do Estado em um ponto de vista que contesta o discurso de tradição europeia.

A partir desse momento, Pierre Clastres se apresenta como um bom companheiro de caminha. As investigações de antropologia política apresentam interessantes pistas a respeito de contextos sociais muito diversos do modelo europeu, demonstrando com rigor "que a opção pelo Estado e o poder coercitivo que o funda não é mais do que isso: uma entre várias outras possibilidades de organização social" (Matos 2014:175).

Ao estudar as comunidades indígenas da América do Sul, Clastres apresenta um primeiro diagnóstico que diz respeito à etnografia, análise que estabelece um critério de distinção entre o modelo societário europeu e o ameríndio, com destaque para o sentido de uma ausência, o que caracterizaria os modelos de sociedade latino-americanos como sociedades incompletas (Clastres 1990:132).

Nas palavras de Clastres (1990:132):

Não são exatamente verdadeiras sociedades - não são policiadas -, e subsistem na experiência talvez dolorosa de uma falta - falta do Estado - que elas tentariam, sempre em vão, suprir. De um modo mais 
ou menos confuso, é realmente o que dizem as crônicas dos viajantes ou os trabalhos dos pesquisadores: não se pode imaginar a sociedade sem Estado, o Estado é o destino de toda sociedade. Descobre-se nessa abordagem uma fixação etnocentrista tanto mais sólida quanto é ela, o mais das vezes, inconsciente.

As sociedades latino-americanas seriam então sociedades sem Estado, o que no entendimento de Clastres configura uma sociedade primitiva. Note-se que o uso desses termos não pode significar o rebaixamento dessas organizações sociais, sob pena de prejudicar as condições de possibilidade de se reconhecer a antropologia política como ciência (Clastres 1990:132). Para Clastres (2014:137) "é conforme a presença ou ausência do Estado que se opera uma primeira classificação das sociedades, pela qual elas se distribuem em dois grupos: as sociedades sem Estado e as sociedades com Estado, as sociedades primitivas e as outras". Essa caracterização, no entender de Clastres, não deixa margem para compreender as sociedades com Estado como idênticas entre si, mas permitem a aproximação de outra imagem do etnocentrismo que se liga ao já mencionado argumento de filosofia da história que ressalta nessa última a ideia de progresso, ou seja, a história teria um único sentido, "de que toda sociedade está condenada a inscrever-se nessa história e a percorrer as suas etapas que, a partir da selvageria, conduzem à civilização" (Clastres 1990:133).

Uma abordagem dessa natureza nos leva a observar que o modelo socie- tário dos povos latino-americanos se organiza de modo diverso do mundo europeu e, por consequencia, há impactos consideráveis na maneira de se pensar e exercer o poder político. Em uma abordagem orientada pelo relativismo cultural ${ }^{11}$, Clastres destaca que nas sociedades da América do Sul o poder político não é algo separado do corpo social sobre o qual é exercido (Clastres 2014:137).

A forma de organização político-societária nas sociedades da América Latina contrasta com o modelo europeu na medida em que a esfera do poder político não pode ser distinguida do aspecto social. O pensamento da tradição europeia vislumbra no político algo de essencial ao homem, mas, ao mesmo tempo, destaca no político uma "divisão social entre dominantes e dominados, entre os que sabem, e, portanto, mandam, e os que não sabem, e portanto obedecem" (Clastres 2014:138). A caracterização é feita a partir do social, organizado em estruturas hierárquicas e relações de mando e obediência, que configuram as relações políticas e de poder e, onde não existam essas últimas, materializa-se a ausência, o infrassocial e a não sociedade (Clastres 2014:138).

Ressalta Clastres (2014:141):

Percebe-se bem que tal julgamento não é, na verdade, senão um preconceito ideológico, implicando uma concepção da história como movimento necessário da humanidade ao longo das figuras do social que se engendram e se encadeiam mecanicamente. Mas digamos que se recuse essa neoteologia da his- 
tória e seu continuísmo fanático: com isso as sociedades primitivas deixam de ocupar o grau zero da história, já que estariam grávidas ao mesmo tempo de toda a história por vir, inscrita antecipadamente em seu ser.

O julgamento dos conquistadores a respeito de tal organização no reino das maravilhas seria feito no sentido de uma depreciação do modelo político-societário e recusa dessa forma de organização como selvageria. Conforme Clastres (2014:138) “constatando que os 'chefes' não possuíam nenhum poder sobre as tribos, que ninguém mandava e ninguém obedecia, eles disseram que esses povos não eram policiados, que não eram verdadeiras sociedades: selvagens "sem fé, sem lei, sem rei".

É curioso notar o relato a respeito da chefia indígena, que invariavelmente é representada como o senhor da comunidade, um personagem que materializaria o arbítrio, o que se afigura uma verdadeira falácia, já que os líderes são desprovidos de poder no que diz respeito a uma manifestação hierárquica desse último, o que não significa ausência completa de significação societária. O chefe indígena, enquanto servidor e não senhor da comunidade, conecta-se a ela mediante a realização de tarefas que lhe são incumbidas, especialmente aquelas de se pronunciar pela comunidade, "com vistas a afirmar sua especificidade, sua autonomia, sua independência em relação às outras comunidades" (Clastres 2014:139).

$\mathrm{O}$ que se percebe a partir desses elementos apresentados por Clastres é que as sociedades sem Estado da Amé- rica Latina se organizavam em torno a certo igualitarismo de base e que se expressa de maneiras bastante diversificadas. No entanto, o ponto fundamental é observar que essa forte noção de igualdade se apresenta como uma grande recusa a ideia de poder que se separa da sociedade, organizando-se de maneira hierárquica e, via de consequência, impondo-se enquanto realidade autônoma (Matos 2014:176).

O modelo de arranjo societário existente nas sociedades sem Estado é bastante diferente do protótipo europeu - em alguns casos os estados colonizadores se estruturavam de maneira feudal -, e do nosso paradigma atual, formas de disposição do poder em que se submete a sociedade ao Estado como configuração de proteção e construção de um discurso de estatolatria, com a possibilidade de se reconhecer que em alguns casos o poder é exercido contra a sociedade. Assim, o ser da sociedade sem estado é a indivisão, visto que impede o surgimento de uma esfera de poder que acarrete a separação da sociedade com a diferenciação entre os que mandam e os que obedecem, autorizando a dominação do chefe sobre a sociedade (Clastres 2014:237).

De acordo com tal perspectiva, a sociedade sem estado funciona para que não existam desigualdades, manifestam-se contra a exploração e divisões sociais e pretendem que essas figuras não sejam possíveis (Clastres 2014:238). No entender de Andityas Matos (2014:176) "no mundo dos selvagens o poder político se confunde com a própria sociedade, e é essa coincidência que torna possível a negação de coisas similares 
ao Estado e à economia de mercado, construtos separados da comunidade". Ao que parece há necessidade de se recusar a história oficial, o historicismo, para se pensar criticamente o arquétipo societário em que vivemos e se de fato só é possível (sobre)viver em uma estrutura estatal que se estabelece pela divisão social do trabalho e que funciona a partir do sistema econômico capitalista. Com os diagnósticos de Clastres apresenta-se possível negar o caráter a-bistórico das sociedades primitivas latino-americanas e, conforme já mencionado anteriormente, podemos pensar com Benjamin e Dussel, que a história é uma narrativa dos vencedores e, portanto, uma história do poder que se mostra possível pelo monopólio da violência, desse modo, "ao contrário do que fazemos, os indígenas referidos por Clastres não escrevem e apresentam a si mesmos algo como uma história, ou seja, uma narrativa em que os conflitos sociais são reduzidos a momentos dialéticos ideais que sempre apontam para o télos do Estado" (Matos 2014:178).

Ainda, diz Andityas Matos (2014:178):

Somente recusando o peso da história oficial será possível construir alternativas viáveis diante do capitalismo, que já se naturalizou enquanto a única 'história' capaz de possibilitar a autocompreensão de nossas sociedades. Para criticar essa visão monolítica é necessário levar a sério o olhar dos "primitivos". Sem uma história que os limite, eles se encontram no aberto de uma realidade em que comando e obediência não fazem sentido.
Por conseguinte, tem que se recusar imagens ideológica e discursivamente construídas a fim de indicar a possibilidade de reconhecimento de superioridade de uma cultura sobre outras, com o objetivo de que se manifeste a recusa da historiografia tradicional. Somente com esse colocar-se contra se torna possível o reconhecimento de que os modos de vida das sociedades sem estado não representam a selvageria, arranjos sociais que viveriam em processos econômicos de subsistência, em que se nega o trabalho e se privilegia a guerra. Feitas estas considerações acerca do discurso da historiografia tradicional, importa considerar que no continente americano como um todo ocorreram inúmeras manifestações dos povos ameríndios contra a ideia de organização social em um Estado dos colonizadores, com alguns casos famosos como a guerra de Nuvem Vermelha na América do Norte que após dois anos de resistência vence a guerra (Brown 2014:158). Na América Latina o processo de colonização já fazia suas vítimas entre os povos nativos e, nas palavras de Eduardo Galeano (1986:49-50):

Em 1581, Felipe II afirmara, perante o tribunal de Guadalajara, que um terço dos indígenas da América já tinha sido aniquilado, e aqueles que ainda viviam eram obrigados a pagar tributos pelos mortos. O monarca disse, além disso, que os índios eram comprados e vendidos. Que dormiam na intempérie. Que as mães matavam seus filhos para salvá-los dos tormentos das minas [...]. A escravidão greco-romana ressuscitava de fato, num mundo distinto; ao infortúnio dos 
índios dos impérios aniquilados da América hispânica é preciso somar o terrível destino dos negros arrebatados às aldeias africanas para trabalhar no Brasil e nas Antilhas. A economia colonial latino-americana dispôs da maior concentração de força de trabalho até então conhecida, para possibilitar a maior concentração de riqueza que jamais possuiu qualquer civilização na história mundial.

Nos termos de Galeano o quadro era de uma violenta maré de cobiça e horror que se abateu sobre os povos latinos com a realização de um verdadeiro genocídio indígena ${ }^{12}$, mesmo que com o início de uma pretensa proteção dos povos nativos pela legalidade, com o reconhecimento desses como seres dotados de alma, contudo, "a ficção da legalidade amparava o índio; a exploração da realidade sangrava-o" (Galeano 1986:50).

Diante de tal situação de violência organizada da sociedade estatal dos colonizadores civilizados, só restou aos povos nativos da América resistir, uma vez que "a esperança de renascimento $\mathrm{da}$ dignidade perdida incendiaria numerosas sublevações indígenas" (Galeano 1986:55). Não seria possível nos limites desse trabalho a reconstrução de todos os focos e narrativas a respeito da resistência, mas alguns exemplos, como o sítio a Cuzco de 1781 realizado por Túpac Amaru, podem ilustrar as mobilizações indígenas contra o Estado do mundo eurocêntrico, contra a violência organizada pelos colonizadores e que podem nos dar elementos a fim de questionar o universo das sociedades sem Estado como de organizações sociais que vivem na selvageria e na guerra, uma vez que no pensamento indígena de linhas metafísicas o Um é o mal e o Um é o Estado ${ }^{13}$, assim, a resistência ameríndia "é a tentativa heróica de uma sociedade primitiva para abolir a infelicidade na recusa radical do Um como essência universal do Estado" (Clastres 1990:151).

Pierre Clastres (1990:152) argumenta que a história das sociedades primitivas ou dos povos sem história é a da luta contra o Estado, o que não necessariamente significa uma vida selvagem e sem regras de convívio, e, conforme já mencionado, o objetivo é impedir o aparecimento de um poder descolado do contexto societário e, não obstante, "as normas das sociedades sem Estado são igualitárias, dado que sustentadas por um consenso social interno" (Matos 2014:179).

Uma cultura latino-americana resistiu e se forjou nas sombras da dominação eurocêntrica, como uma cultura popular. De acordo com Dussel (2016:13):

En el campo, más allá de México, Lima o Chuquisaca, la cultura mestiza, criolla, indígena gestaba principalmente en su seno la cultura popular latinoamericana en su segunda etapa (la primera habíase dado en Amerindia). Las clases dominadas iban constituyendo un pueblo en sentido estricto y con él emergía ya una nueva cultura creada en las sombras, en la resistência, en la tradición oral, en la danza, en la fiesta, en la música, en el trabajo cotidiano, en la memoria.

De tal modo, parece possível vislumbrar toda resistência existente na América Latina como o exercício do direi- 
to à resistência a qualquer forma de opressão do poder político e de injustiças e, muito especialmente, de uma luta da sociedade latino-americana contra o Estado, justificando-se, desse modo, a desobediência. Ao se concordar com a transcrição de Enrique Dussel linhas atrás, torna-se admissível pensar a possibilidade de uma desobediência epistêmica, uma das propostas de resgate da cultura latino-americana como sugestão de uma opção descolonial ${ }^{14}$ a fim de se desvencilhar dos códigos de operações - inclusive biopolíticos -, que são controlados pela economia e teoria política eurocêntricas (Mignolo 2008:287).

\section{CONSIDERAÇÕES FINAIS}

Das veias abertas na América Latina resta importante voltar à atenção para suas cicatrizes, deixadas pela experiência de dor, sofrimento e resistência de seus povos, retorno que agora se faz como memória, lembrança e reflexão acerca da promessa da história de que no ingresso em seu continuum tudo ficaria bem, dentro do padrão civilizatório.

Nesse horizonte de perspectiva, a pretensão foi a de uma análise crítica das táticas discursivas como práticas de poder que envolvem o universo do discurso e construíram imagens como as do selvagem e do bárbaro com o propósito de justificar as pretensões de tomada da terra na América. Para tanto, o discurso arquiteta as subjetividades daqueles que serão oprimidos e, ainda, os institutos jurídicos - como, por exemplo, a occupatio e o descobrimento, entre outros -, objetivam legalizar os processos coloniais de possessão do solo do novo mundo. A partir de tais estratégias, torna-se possível ao invasor justificar toda a sorte de violências contra os povos nativos, com a intenção de apropriação de suas riquezas.

Uma das pretensões de se contestar o historicismo tradicional foi a de investigar uma linha de contra discurso ou um pensar a história a contra pêlo, que nos possibilita fazer emergir as táticas do poder, autorizando o reconhecimento das manifestações dos povos latino-americanos não como barbárie, mas, sim, como a mais legítima resistência ao modelo de Estado do europeu colonizador. A resistência latino-americana se faz contra o Estado europeu, uma vez que os arranjos societários dos povos da América mantinham o poder político dentro de uma perspectiva de sociedade e não como algo fora dela, bem como havia outro modo de organização da vida, com a existência de normas de convívio igualitárias.

Por fim, o que houve na América e, em especial no espaço latino-americano, foi uma luta da sociedade contra o Estado, compreendida aqui como o exercício legítimo de um direito de resistência às violências praticadas contra os povos ameríndios. Talvez, o mais importante hoje seja a tomada de consciência que o epistemicídio do passado se transforma em diferentes estratégias de dominação no presente, com novas práticas de violência e de domínio que exigem resistência e novas modalidades de desobediência, quem sabe até mesmo epistêmica, como, por exemplo, a opção descolonial. Assim, em nossos dias parece importante recordar o canto imortal de Mercedes Sosa 
aos corações da América Latina que diz "te han sitiado corazón y esperan tu renuncia, los únicos vencidos corazón, son los que no luchan. No te entregues corazón libre, no te entregues".

\section{NOTAS}

${ }^{1}$ A tradição dos oprimidos nos ensina que o "estado de exceção" no qual vivemos é a regra. Precisamos chegar a um conceito de história que dê conta disso. Então surgirá diante de nós nossa tarefa, a de instaurar o real estado de exceção; e graças a isso, nossa posição na luta contra o fascismo tornar-se-á melhor. A chance deste consiste, não por último, em que seus adversários o afrontem em nome do progresso como se este fosse uma norma histórica. O espanto em constatar que os acontecimentos que vivemos "ainda" sejam possíveis no século XX não é nenhum espanto filosófico. Ele não está no inicio de um conhecimento, a menos que seja o de mostrar que a representação da história de onde provém aquele espanto é insustentável (Benjamin 2005:83).

${ }^{2}$ A expressão dispositivo carrega o sentido usualmente dado por Foucault e designa as estruturas do conhecimento e os vários mecanismos institucionais, físicos e administrativos, que propiciam e mantém o exercício de poder dentro do corpo social. Agamben generaliza esse conceito foucaultiano e compreende por dispositivo qualquer coisa que possa capturar, orientar, determinar, interceptar, modelar, controlar e assegurar os gestos, as condutas, as opiniões e os discursos dos seres viventes.

${ }^{3}$ Dee Brown, em seu conhecido Enterrem meu coração na curva do rio, reproduz interessante texto de Colombo se reportando ao seu soberano, como relato dos povos da América, a saber: “"Tão afáveis, tão pacíficos, são eles [...] que juro a Vossas Ma- jestades que não há no mundo uma nação melhor. Amam a seus próximos como a si mesmos, e sua conversação é sempre suave e gentil, e acompanhada de sorrisos; embora seja verdade que andam nus, suas maneiras são decentes e elogiáveis'. Claro que tudo isso foi tomado como sinal de fraqueza, senão de barbárie” (Brown 2014:19). Relata ironicamente Brown que Colombo, por estar bem-intencionado, fica convencido de que esse povo deveria adotar os costumes europeus, trabalhar, plantar, etc.

${ }^{4}$ Roberto Bueno (2014:478) considera que "a violência não encontra acolhida senão em ambientes nebulosos, obscuros, ambíguos, ali onde a transparência não é valor vigente na órbita pública".

${ }^{5}$ As traduções são de minha autoria, salvo indicação em contrário.

${ }^{6}$ Conforme Eduardo Galeano (1986:24) "A Espanha vivia o tempo da reconquista. 1492 não foi só o ano do descobrimento da América, o novo mundo nascido do equívoco de consequências grandiosas. Foi também o ano de consequencias grandiosas". A guerra santa cristã travada contra o Islã pela reconquista esgotava as riquezas da coroa espanhola. Nesse período a "rainha Isabel fez-se madrinha da Santa Inquisição. A façanha do descobrimento da América não podia explicar-se sem a tradição militar de guerra de cruzadas que imperava na Castela medieval [...]. O papa Alexandre VI, que era espanhol, converteu a rainha Isabel em dona e senhora do Novo Mundo" (Galeano 1986:24).

${ }^{7}$ A célebre peça do dramaturgo grego pertence ao gênero literário das tragédias, e em sua trilogia ilustra uma série de características que se atribuem ao drama desde a Antiguidade; logo, esse escrito do teatro trata de assuntos políticos sobre o governo e o destino de Tebas e, além disso, é capaz de provocar ponderações acerca do jurídico até nossos dias. 
${ }^{8}$ Notes-se que há quem defenda que ideia de um direito de resistência também está presente no pensamento de Thomas Hobbes, quando esse último afirma que dá passagem do estado de natureza ao estado civil o indivíduo leva consigo o dever/direito de lutar por sua própria vida, ou seja, haveria um direito de autopreservação em Hobbes, oponível inclusive contra o poder soberano.

${ }^{9}$ Nas palavras de Thoreau (2012:10): “[...] a massa de homens serve ao Estado não na qualidade de homens, mas como máquinas, com seus corpos. [...] Na maioria dos casos, não há, em absoluto, o livre exercício do julgamento ou do senso moral".

${ }^{10}$ A respeito da história social, destaca Koselleck (2015:97): “Constituem objeto da história social a investigação das formações das sociedades ou as estruturas constitucionais, assim como as relações entre grupos, camadas e classes; ela investiga as circunstâncias nas quais ocorreram determinados eventos, focalizando as estruturas históricas de médio e longo prazos, bem como suas alterações. A história social pode ainda investigar teoremas econômicos, por força dos quais se pode questionar os eventos singulares e os desenvolvimentos políticos dos fatos".

${ }^{11}$ Perspectiva que nega a superioridade de uma cultura sobre outra, portanto, da civilização europeia em relação a outros sistemas societários e renuncia ao reconhecimento de uma hierarquia de valores, reconhecendo a coexistência de múltiplas culturas e diferenças socioculturais.

${ }^{12}$ Conforme Galeano (1986, p. 50) "Os indios das Américas somavam entre 70 e 90 milhões de pessoas, quando os conquistadores estrangeiros apareceram no horizonte; um século e meio depois tinham-se redurido, no total, a apenas 3,5 milhöes".

${ }^{13}$ Interessante notar a antecedência e a proximidade de tal reflexão com o texto de $\mathrm{La}$
Boétie do Contra Um, seu famoso Discurso sobre a Servidão Voluntária, em que é digno de seu espanto o fato de milhões de homens serem subjugados a um só, de qualidades muitas vezes desumanas e cruéis ( $\mathrm{La}$ Boétie 2009:9).

${ }^{14}$ Conforme Mignolo (2008:290): “A opção descolonial é epistêmica, ou seja, ela se desvincula dos fundamentos genuínos dos conceitos ocidentais e da acumulação de conhecimento. Por desvinculamento epistêmico não quero dizer abandono ou ignorância do que já foi institucionalizado por todo planeta (por exemplo, veja o que acontece agora nas universidades chinesas e na institucionalização do conhecimento). Pretendo substituir a geo- e a política de Estado de conhecimento de seu fundamento na história imperial do Ocidente dos últimos cinco séculos, pela geo-política e a política de Estado de pessoas, línguas, religiões, conceitos políticos e econômicos, subjetividades, etc. que foram racializadas (ou seja, sua óbvia humanidade foi negada). Dessa maneira, por 'Ocidente' eu não quero me referir à geografia por si só, mas à geopolítica do conhecimento".

\section{REFERÊNCIAS}

Agamben, G. 2004. Estado de Exceção. Trad. Iraci D. Poletti. São Paulo: Boitempo. . 2007. Homo Sacer: o poder soberano e a vida nua I. Trad. Henrique Burigo. Belo Horizonte: Editora da UFMG.

Barthes, R. 1997. Aula. Trad. Leyla Perrone-Moisés. São Paulo: cultrix.

Benjamin, W. 1986. Crítica da violência crítica do poder. In: Documentos de cultura, documentos de barbárie. São Paulo: Cultrix/ USP, pp 160-175.

2005. Teses sobre o conceito de história. In: LÖWY. M. Walter Benjamin: aviso 
de incêndio. Um leitura das teses 'sobre o conceito de história'. Trad. Wanda Nogueira Caldeira Brant, Jeanne Marie Gagnebin, Marcos Lutz Müller. São Paulo: Boitempo.

.2011. Para uma crítica da violência. In: Escritos sobre mito e linguagem. Org. Jeanne Maria Gagnebin. Trad. Susana Kampff Lages e Ernani Chaves. São Paulo: editora 34.

.2013. Experiência e pobreza. In: $O$ anjo da história. Organização e Tradução de João Barrento. $2^{\mathrm{a}}$ ed. Belo Horizonte: Autência editora.

Boron, A. 2003. Estado, capitalismo y democracia en América Latina. $1^{a}$ ed. Buenos Aires: Clacso.

Brown, D. 2014. Enterrem meu coração na curva do rio. Trad. Geraldo Galvão Ferraz e Lola Xavier. Porto Alegre-RS: L\&PM. 2014.

Bueno, R. 2013. Barbárie: literatura e filosofia moral. Boletín Mexicano de Derecho Comparado, no 13, p. 471-498.

2015. Educação, democracia e direitos humanos: a teoria da sociedade aberta democrática e o caso latino-americano. In: SANCHES, R. C. F; BERTHO, P. R. (orgs.) A construcão do saber jurídico: revisitando as possibilidades do ensino do direito. São Paulo: Max Limonad.

Bulygin, E. 1987. Sobre el status ontológico de los derechos humanos. In: Doxa. Cuadernos de Filosofia del Derecho, Alicante. n. 4, p. 79-84.

Carvajal A., P. 1992. Derecho de resistencia, derecho a la revolución, desobediencia civil: Una perspectiva histórica de interpretación. La formación del derecho público y de la ciencia política en la temprana Edad Moderna. Revista de Estudios Politicos (Nueva Época), n. 76. Abril-Junio.

Clastres, P. 1990. A sociedade contra o Estado: pesquisas de antropologia politica. Trad. Theo Santiago. Francisco Alves.
2014. Arqueologia da violência: pesquisas de antropologia politica. Trad. Paulo Neves. São Paulo: Cosacnaify.

Dussel, E. 1988. ¿Descubrimiento o invasion de America?. Concilium: revista internacional de teologia, no 220, p. 481-488.

. Europa, modernidad y eurocentrsimo. Disponível na internet: http://enriquedussel.com/txt/1993-236a.pdf. Acesso em 21/06/2011.

. Eurocentrismo y modernidad (introducción a las lecturas de Frankfurt). Disponível na internet: http://www.enriquedussel.com/DVD $\% 20$ Obras $\% 20$ Enrique\%20Dussel/Textos/c/243.1993/ articulo.pdf. Acesso em: 23/03/2016a.

. Cultura latinoamericana y filosofia da liberacion (cultura popular revolucionária, más allá del populismo y del dogmatismo). Disponível na internet: http://www. enriquedussel.com/DVD $\% 20 \mathrm{Obras} \% 20$ Enrique\%20Dussel/Textos/c/1984-149. pdf. Acesso em: 23/03/2016b.

Foucault. M. 2010. Em defesa da sociedade: curso no Collège de France (1975-1976). Trad. Maria Ermantina Galvão. $2^{\mathrm{a}} \mathrm{ed}$. São Paulo: Martins Fontes.

2013. Trad. Laura Fraga de Almeida Sampaio. São Paulo: Loyola. 2013.

Galeano, Eduardo. 1986. As veias abertas da América Latina. Trad. Galeno de Freitas. 23a Ed. Rio de Janeiro: Paz e Terra.

Giacoia Junior, O. 2008a. Notas sobre direito, violência e sacrifício. Dois pontos, Curitiba, São Carlos, vol. 5, n. 2, pp. 33-47.

2008b. Sobre direitos humanos na era da bio-política. Kriterion, Belo Horizonte, $n^{\circ} 118$, pp. 267-308.

2014. Violência e racionalidade jurídica: a potência dos meios. Revista Brasileira de Estudos Políticos. Belo Horizonte, $\mathrm{n}^{\circ}$ 108, p. 243-291. 
2015a. Ética, direito e política em tempos de biopoder. In: Giacoia Junior, O; Ramiro, C. H. L.; Ricci, L. A. L (Orgs.). Responsabilidade e futuro: bioética, biopolitica, biopoder e os desafios para a reflexão e ação. São Paulo: LiberArs.

.2015b. Civilização e barbárie. In: Novaes, Adauto (org.). Fontes passionais da violência. São Paulo: editora Sesc-São Paulo.

Koselleck, Reinhart. 2015. Futuro passado: contribuição à semântica dos tempos históricos. Trad. Wilma Patrícia Maas e Carlos Almeida Pereira. Rio de Janeiro: Contraponto / Editora PUC-Rio.

La Boétie, E. 2009. Discurso sobre a servidão voluntária. Brasília: LGE editora.

Martínez, G. 1994. La universalidad de los derechos humanos. Doxa, cuadernos de la Filosofia del Derecho. No 15-16, p. 613 - 633. 1994.

1988/89 Desobediencia civil y objeción de conciencia. Anuario de Derechos Humanos, $\mathrm{n}^{\circ}$ 5, p. 159-176.

Matos, A. S. M. C. 2014. A multidão contra o estado: rumo a uma comunidade do inapropriável. In: Revista Brasileira de Estudos Politicos. Belo Horizonte, no 108, p. $145-$ 184.

;2014. Souza, J. K. S. Entre consciência individual e autoridade estatal: breves reflexões sobre a desobediência civil no estado democrático de direito. Revista da faculdade de direito da UFG, v. 38, n 2, p. 149-176.

Mignolo, W. D. 2008. Desobediência epistêmica: a opção descolonial e o significado de identidade em política. Trad. Angela Lopes Norte. Cadernos de Letras UFF. Dossiê: Literatura, língua e identidade, $n^{\circ} 34$, p. 287-324.

Muñoz, M. E; Grisales, D. C. S. 2014. El epitemicidio indígena latinoamericano. Algunas reflexiones desde el pensamiento critico decolonial. Revista CES Derecho, vol. 5, no 2, p. 154-164.

Neumann, F. 1969. Estado democrático e estado autoritário. Trad. Luiz Corção. Rio de Janeiro: Zahar Editores.

Ramiro, C. H. L. 2013. Heurística do poder e perspectivas críticas ao Estado de Direito: uma leitura a partir de Walter Benjamin. Revista de Informação Legislativa, $\mathrm{n}^{\circ} 198, \mathrm{p}$. 239-254.

;2013. Souza, T. C. Sobre hermenêutica, direito e literatura: itinerários filosóficos, políticos e jurídicos de Antígona. Reflexión Politica, Bucaramanga-Colombia: Universidad Autónoma, vol. 15, no 29, p. 74-83.

Schmitt, C. 2005. El nomos de la tierra en el Derecho de Gentes del Jus publicum europaeum. Buenos Aires: editorial Struhart \& Cía.

. El Orden Del Mundo Despues De La Segunda Guerra Mundial. Dispoivel na Internet: file:///C:/Documents $\% 20$ and $\% 20$ Settings/User/Meus $\% 20$ documentos/Downloads/Dialnet-ElOrdenDelMundoDespuesDeLaSegundaGuerraMundial-2048059.pdf. Acesso em 20/02/2014.

Sófocles. 1965. Antígona. Transc. Guilherme de Almeida. Petrópolis: Vozes.

Thoreau, H. D. 2012. A desobediência civil. Trad. José Geraldo Couto. São Paulo: Penguin Classics Companhia das Letras. 2012.

Wolff, F. 2004. Quem é o bárbaro? In: Novaes, Adauto (org.). Civilização e barbárie. São Paulo: Companhia das Letras. 